\title{
Valor nutritivo de silagens de capim-elefante emurchecido ou com adição de farelo de cacau ${ }^{1}$
}

\section{Gleidson Giordano Pinto de Carvalho², Rasmo Garcia ${ }^{3,7}$, Aureliano José Vieira Pires ${ }^{4,7}$, Odilon Gomes Pereira ${ }^{3,7}$, José Augusto Gomes Azevêdo ${ }^{5}$, Bruna Mara Aparecida de Carvalho ${ }^{6}$, Jucilene Cavali ${ }^{2}$}

\footnotetext{
1 Parte da tese de Mestrado do primeiro autor apresentada à UFV, Viçosa, MG.

2 Doutorando em Zootecnia, UFV, Viçosa, MG, Bolsista do CNPq.

${ }^{3}$ DZO, UFV, Viçosa.

${ }^{4}$ DTRA/UESB, Itapetinga, BA.

${ }^{5}$ Doutorando em Zootecnia, UFV, Viçosa, MG. Professor, UESC, Ilhéus, BA.

${ }^{6}$ Mestranda em Ciência e Tecnologia de Alimentos, UFV, Viçosa, MG.

${ }^{7}$ Pesquisador do CNPq.
}

RESUMO - O experimento foi conduzido para avaliar o valor nutritivo da silagem de capim-elefante produzida com o capim emurchecido ou adicionada de diferentes níveis de farelo de cacau. O capim-elefante foi colhido aos 50 dias de rebrota após o corte de uniformização e submetido aos seguintes tratamentos na ensilagem: capim-elefante emurchecido ao sol por 8 horas, e capim-elefante sem emurchecimento com 0, 7, 14, 21 e 28\% de farelo de cacau (FC) (\% da matéria natural). Foram utilizadas quatro repetições por tratamento; o material foi acondicionado em silos de PVC com 0,15 m de diâmetro e 0,3 m de altura, adotando-se compactação de $500 \mathrm{~kg} / \mathrm{m}^{3}$. A inclusão do farelo de cacau na ensilagem do capim-elefante mostrou-se eficiente em aumentar o teor de MS da silagem. A inclusão de FC no nível de 7\% permitiu produção de silagem com teor de MS semelhante ao da silagem de capim emurchecido. As silagens com FC apresentaram maiores teores de NT, EE, lignina, NIDN e NIDA, no entanto, os teores de FDN, FDA CEL, HEM, cinzas e NDT e a DIVMS diminuíram com a adição de farelo de cacau. O NDT estimado para a silagem de capim emurchecido foi superior ao obtido nas demais silagens, com e sem farelo de cacau. Embora o FC tenha promovido redução da DIVMS, sua inclusão nos níveis de 7 e 14\% proporcionou boa digestibilidade das silagens (acima de 60\%). O emurchecimento do capim-elefante e a adição de FC podem ser alternativas para aumentar o teor de MS da silagem e garantir a produção de silagens de bom valor nutritivo.

Palavras-chave: forrageira, Pennisetum purpureum, subproduto, Theobroma cacao

\section{Nutritive value of elephantgrass silage wilted or with addition of cocoa meal}

\begin{abstract}
The experiment was carried out to evaluate the nutritive value of elephant grass silage wilted under the sun light for eight hours. Other treatments involved the same elephant grass without exposing to sun light but with addition of $0,7,14,21$, and $28 \%$ of cocoa meal (CM) at the ensilage process. The PVC silos used in the experiment measured $0.15 \mathrm{~m}$ of diameter and $0.30 \mathrm{~m}$ of height. During the ensiling process the forage was compressed until reach $500 \mathrm{~kg} / \mathrm{m}^{3}$. The addition of CM on elephantgrass during the ensiling process increased efficiently the silage DM concentration. The treatment of $7 \%$ addition of $\mathrm{CM}$ resulted in DM concentration similar to the wilted treatment. The treatments involving addition of CM presented high TN, EE, LIG, NDIN, and ADIN concentrations. Reductions in NDF, ADF, CEL, HEM, ash, TDN, and IVDMD concentrations were detected with the addition of CM. The estimated TDN of wilted treatment was greater than the other treatments with or without CM. Although the CM reduced IVDMD, the 7 and 14\% levels of CM inclusion resulted in elevated digestibility over 60\%. The wilting and CM addition may be used as alternatives to increase silage DM concentration.
\end{abstract}

Key Words: roughage, Pennisetum purpureum, byproduct, Theobroma cacao

\section{Introdução}

A irregularidade das chuvas constitui fator limitante à produção de forrageiras, tanto para espécies exóticas como para as nativas. Todavia, além da adaptação edafoclimática das espécies, o manejo inadequado pode impedir o bom aproveitamento de forrageiras com alto potencial produtivo.

A ensilagem de forrageiras com baixo teor de MS quase sempre resulta em silagem de baixa qualidade, em decorrência de problemas como a elevada produção de efluentes e o 
desenvolvimento de bactérias do gênero Clostridium, que ocasionam perdas de MS e do valor nutritivo do material. Além disso, o consumo de MS pode ser reduzido quando forragens são fornecidas com alto teor de umidade (McDonald et al., 1991).

Na tentativa de aumentar o teor de MS e a concentração de carboidratos solúveis de gramíneas como o capimelefante no momento da ensilagem, têm-se recomendado técnicas como o emurchecimento da forragem e o uso de aditivos (Tosi et al., 1995, 1999). Todavia, a perda de umidade por exposição ao sol nem sempre é satisfatória, pois o diâmetro dos colmos do capim-elefante dificulta a migração de água do interior para a periferia (Tosi et al., 1999). O emurchecimento do capim aumenta o tempo entre o corte e a vedação do silo e resulta em maiores perdas, em decorrência do processo respiratório e da atividade proteolítica da planta, que provocam redução dos substratos fermentáveis e aumento do nitrogênio não-protéico (McDonald et al., 1991). Além disso, a adoção desta prática aumenta os gastos com mão-de-obra (Souza et al., 2003).

Por outro lado, alguns autores (Machado Filho \& Mühlbach, 1986; Vilela, 1990) têm observado que, deixando o capim-elefante cortado e exposto ao sol por 6 a 12 horas, ocorre aumento no teor de MS, que, apesar de não permitir a obtenção de material com 30 a 35\% de MS, desejável para a ensilagem (Muck, 1988), propicia a obtenção de silagens de boa qualidade.

Além do emurchecimento, outras alternativas podem ser adotadas para a ensilagem do capim-elefante quando novo. Tanto o rolão de milho (Andrade, 1995) quanto o grão de milho triturado têm sido adicionados na ensilagem do capim-elefante por possibilitarem a obtenção de silagens com fermentação adequada e nutricionalmente convenientes. Resíduos de culturas, como a casca de café, têm sido adicionados no momento da ensilagem do capim-elefante com $14,8 \%$ de MS. Segundo Souza et al. (2003), a casca de café, quando adicionada em níveis iguais ou superiores a $17,4 \mathrm{~kg} / 100 \mathrm{~kg}$ de forragem fresca, mostrou-se um bom aditivo para ensilagem do capim-elefante com alto teor de umidade.

O farelo de cacau, um subproduto resultante da industrialização da amêndoa do cacau para obtenção da manteiga do cacau e do chocolate, também tem sido utilizado com sucesso na alimentação de ruminantes. Segundo Silva et al. (2005), a produção brasileira de farelo de cacau em 2000 foi de, aproximadamente, 20.000 t. Considerando a disponibilidade desse subproduto agrícola (o farelo representa $10 \%$ da produção das amêndoas secas de cacau) nas regiões produtoras, seus conteúdos de MS (86,14\%) e PB (13,62\%) e suas propriedades higroscópicas, o farelo de cacau pode atuar como potencial aditivo se adicionado ao capimelefante no momento da ensilagem por promover acréscimo no teor de MS e possibilitar, portanto, a obtenção de silagem de bom valor nutritivo.

O experimento foi conduzido para avaliar o valor nutritivo da silagem de capim-elefante (Pennisetum purpureum, Schum cv. Napier) emurchecido ou adicionado de diferentes níveis de farelo de cacau (Theobroma cacao L.).

\section{Material e Métodos}

O capim-elefante (Pennisetum purpureum, Schum cv. Napier) utilizado foi proveniente de uma capineira estabelecida, adubada com $100 \mathrm{~kg}$ de N/ha, $100 \mathrm{~kg} \mathrm{de} \mathrm{P}_{2} \mathrm{O}_{5} / \mathrm{ha}$ e $60 \mathrm{~kg}$ de $\mathrm{K}_{2} \mathrm{O} / \mathrm{ha}$, utilizando-se, respectivamente, como fontes o nitrocálcio, o superfosfato simples e o cloreto de potássio, em um solo do tipo chernossolo argilúvio, ótico, típico, estruturado hipereutrófico, com textura argilosa, fase floresta subcaducifólia e relevo ondulado (EMBRAPA, 1999), pertencente à Universidade Estadual do Sudoeste da Bahia, UESB, Itapetinga, BA.

O capim foi submetido a um corte de uniformização (a $10 \mathrm{~cm}$ do solo) e, após 50 dias de rebrota, foi colhido manualmente a $10 \mathrm{~cm}$ do solo, sendo picado em ensiladeira estacionária, em tamanho médio de partícula de $2 \mathrm{~cm}$.

Para obtenção das silagens de capim-elefante emurchecido, o capim colhido foi espalhado no campo e, após 8 horas de exposição ao sol, sem revolvimento, foi picado e ensilado. Para as silagens produzidas com farelo de cacau (FC), no entanto, o capim foi triturado em ensiladeira estacionária logo após o corte, sem emurchecimento prévio, e o farelo de cacau foi imediatamente adicionado à mistura, com base na matéria natural (peso/peso), conforme os tratamentos (Tabela 1): A - capim-elefante emurchecido ao sol por 8 horas; B - capim-elefante sem emurchecimento; C capim-elefante mais farelo de cacau (7\%); D-capim-elefante mais farelo de cacau (14\%); E - capim-elefante mais farelo de cacau (21\%); F - capim-elefante mais farelo de cacau (28\%).

O material foi ensilado em silos experimentais de PVC, cilíndricos (0,15 m de diâmetro, 0,3 m de altura), promovendo compactação manual, em densidade de $500 \mathrm{~kg} / \mathrm{m}^{3}$, correspondente a 2,65 kg de matéria natural por silo. Os silos foram vedados com lona plástica nas duas extremidades, com auxílio de arame liso galvanizado e fita plástica e armazenados em galpão coberto durante 45 dias.

Após esse período, os silos foram abertos para coleta de amostras, as quais foram congeladas, devidamente acondicionadas e transportadas para o Departamento de 
Tabela 1 - Composição química, pH e digestibilidade in vitro da MS (DIVMS) do capim-elefante e do farelo de cacau

Table 1 - Chemical composition, $\mathrm{pH}$, and in vitro DM digestibility (DMIVD) of elephantgrass and cocoa meal

\begin{tabular}{|c|c|c|c|}
\hline \multirow[t]{2}{*}{$\begin{array}{l}\text { Item } \\
\text { Item }\end{array}$} & \multicolumn{3}{|c|}{$\begin{array}{c}\text { Capim-elefante } \\
\text { Elephantgrass }\end{array}$} \\
\hline & $\begin{array}{l}\text { Não emurchecido } \\
\text { Not wilted }\end{array}$ & $\begin{array}{l}\text { Emurchecido } \\
\text { Wilted }\end{array}$ & $\begin{array}{l}\text { Farelo de } \\
\text { cacau } \\
\text { Cocoa meal }\end{array}$ \\
\hline MS (DM) & 20,1 & 27,8 & 89,8 \\
\hline $\mathrm{MO}^{1}(\mathrm{MO})$ & 90,4 & 90,2 & 92,6 \\
\hline $\mathrm{PB}^{1}(\mathrm{CP})$ & 8,6 & 8,5 & 13,5 \\
\hline $\mathrm{EE}^{1}$ & 1,7 & 1,8 & 9,9 \\
\hline $\mathrm{FDN}^{1}(N D F)$ & 71,1 & 68,6 & 48,5 \\
\hline $\mathrm{FDN}_{\mathrm{CP}}{ }^{1}\left(N D F_{A P}\right)$ & 67,5 & 65,2 & 43,6 \\
\hline $\mathrm{FDA}^{1}(A D F)$ & 43,6 & 41,3 & 40,0 \\
\hline Cinza $^{1}$ (Ash) & 9,6 & 9,8 & 7,4 \\
\hline Lignina $^{1}$ (Lignin) & 3,3 & 3,3 & 17,9 \\
\hline Celulose $^{1}$ (Cellulose) & 40,3 & 37,9 & 23,1 \\
\hline Hemicelulose $^{1}$ & 27,4 & 27,3 & 8,5 \\
\hline \multicolumn{4}{|l|}{ Hemicellulose } \\
\hline $\mathrm{NIDN}^{1}$ (NDIN) & 0,21 & 0,23 & 1,1 \\
\hline NIDA $^{1}$ (ADIN) & 0,15 & 0,16 & 1,0 \\
\hline NIDN $^{2}$ (NDIN) & 15,2 & 16,9 & 50,5 \\
\hline NIDA $^{2}$ (ADIN) & 10,8 & 11,8 & 47,7 \\
\hline $\mathrm{CT}^{1}(T C)$ & 80,1 & 79,9 & 69,2 \\
\hline $\mathrm{CNF}^{1}$ (NFC) & 12,6 & 14,4 & 25,7 \\
\hline $\mathrm{CHO}^{1}$ & 10,9 & 10,2 & 12,2 \\
\hline $\mathrm{pH}$ & 5,6 & 5,6 & - \\
\hline DIVMS $^{1}$ (IVDMD) & 63,5 & 64,2 & 47,0 \\
\hline
\end{tabular}

$1 \%$ da MS (DM \%); 2 \% do nitrogênio total (total nitrogen \%).

Zootecnia da Universidade Federal de Viçosa para processamento e análises, realizados nos Laboratórios de Forragicultura e de Nutrição Animal.

Parte das amostras foi descongelada à temperatura ambiente, acondicionada em sacos de papel e levada à estufa de ventilação forçada, por 72 horas, a $65^{\circ} \mathrm{C}$. Em seguida, o material foi triturado em moinho tipo Willey com peneira de malha de $1 \mathrm{~mm}$ e submetido a análises para determinação dos teores de nitrogênio total (NT), FDN, fibra em detergente neutro corrigida para de cinzas e proteína (FDNcp), FDA, EE, celulose, hemicelulose, lignina, nitrogênio insolúvel em detergente neutro (NIDN), nitrogênio insolúvel em detergente ácido (NIDA) e cinzas e para estimativa da digestibilidade in vitro da MS (DIVMS), segundo metodologia descrita por Silva \& Queiroz (2002), e nutrientes digestíveis totais (NDT), conforme descrito por Weiss et al. (1992), com modificações sugeridas pelo NRC (2001), representadas pelas equações a seguir:

$$
\mathrm{NDT}=\mathrm{CNFD}+\mathrm{PBD}+(\mathrm{AGD} \times 2,25)+\mathrm{FDND}-7
$$

em que: $\mathrm{CNFD}=0,98\{100-[(\mathrm{FDN}-\mathrm{PBFDN}) *+\mathrm{PB}+\mathrm{EE}+$ Cinzas] \} x FAP;

$\mathrm{PBD}=\mathrm{PB}[-1,2 \mathrm{x}(\mathrm{PBFDA} / \mathrm{PB})]$;

$\mathrm{AGD}=\mathrm{AG}=\mathrm{EE}-1$. Se $\mathrm{EE}<1, \mathrm{AG}=0$;
FDND $=0,75 \times[(F D N-P B F D N) *-\mathrm{Lig}] \times\{1-[\mathrm{Lig} /(\mathrm{FDN}-$ PBFDN)*]0,667\}

* se a FDN for determinada adicionando-se sulfito de sódio, não subtrair a PBFDN

em que: $\mathrm{CNFD}$ = carboidratos não-fibrosos verdadeiramente digestíveis; $\mathrm{PBD}=$ proteína bruta verdadeiramente digestível; AGD = ácidos graxos verdadeiramente digestíveis; FDND = FDN verdadeiramente digestível; PBFDN = proteína bruta ligada à FDN; FAP = fator de ajuste de processamento, neste caso, igual a 1; PBFDA = proteína bruta ligada à FDA; Lig = lignina.

As análises para determinação dos teores de FDN e FDA (Van Soest et al., 1991) foram feitas em autoclave, conforme relatado por Pell \& Schofield (1993).

O delineamento experimental adotado foi o inteiramente casualizado, com seis tratamentos e quatro repetições. O efeito dos níveis de FC foram interpretados por meio das análises de variância e regressão e a comparação entre os níveis de farelo e o emurchecimento foi realizada pelo teste Dunnett (1955), utilizando-se o Statistical Analyses System (SAS, 1999).

\section{Resultados e Discussão}

A exposição do capim-elefante ao sol por 8 horas foi eficiente em reduzir o teor de umidade da gramínea. A adição de farelo de cacau também promoveu redução do teor de umidade de forma satisfatória (Tabela 2); o nível de 7\% de adição do farelo de cacau ao capim-elefante resultou em silagem com teor de MS (24,2\%) similar $(\mathrm{P}>0,05)$ ao da silagem de capim emurchecido (25,3\%). À exceção da silagem produzida com $0 \%$ de farelo de cacau, ou seja, com o capim não emurchecido, na qual o teor de MS (20,1\%) foi inferior ao obtido com o capim emurchecido, as demais silagens (com 14, 21 e 28\% de farelo de cacau) apresentaram teor de MS superior $(\mathrm{P}<0,05)$, com acréscimos, respectivamente, de 5,0; 9,2 e 15,4 unidades percentuais.

O farelo de cacau apresentou excelente potencial de absorção de umidade, uma vez que propiciou acréscimo linear $(\mathrm{P}<0,01)$ no teor de MS das silagens (Tabela 3$)$. Estimado pela equação de regressão, o nível de farelo de cacau a ser adicionado ao capim-elefante aos 50 dias de rebrota para produção de silagem com 30\% de MS foi de 14,4\%. Segundo Muck (1988), o teor de MS da forrageira ideal para produção de silagem de bom valor nutritivo é de $30 \%$. Entretanto, o estádio vegetativo em que o capim-elefante apresenta bom valor nutritivo não coincide com esse teor de MS, sendo necessário, portanto, o pré-tratamento (emurchecimento) antes da ensilagem. Alternativas como o uso de aditivos tem merecido maior destaque nos últimos 
anos, uma vez que a técnica de emurchecimento é muito dispendiosa. De acordo com a equação de regressão, o nível mínimo de farelo de cacau a ser adicionado ao capim-elefante para produção de silagem com teor de MS acima de 25\% é de $7,3 \%$.

Os teores de MO nas silagens com 0 e 7\% de adição de farelo de cacau foram similares ao da silagem de capim emurchecido ( $\mathrm{P}>0,05)$. A análise de regressão indicou que a adição de níveis crescentes de farelo de cacau resultou em efeito linear crescente nos teores de MO da silagem. Uma vez que o teor de cinzas do farelo de cacau foi menor que o do capim-elefante (duas unidades percentuais a menos), era previsível que, com a inclusão desse subproduto, ocorresse aumento nos teores de MO da silagem.

As silagens com 7, 14 e 21\% de farelo de cacau apresentaram teores de nitrogênio total (NT) similares ao obtido na silagem produzida com o capim-elefante emurchecido. Todavia, os resultados encontrados na silagem do capim emurchecido foram superiores e inferiores aos obtidos com 0 e $28 \%$ de farelo de cacau. A adição de farelo de cacau na ensilagem do capim-elefante aumentou de forma linear os teores de NT da silagem (Tabela 3), como conseqüência do maior teor de nitrogênio desse subproduto em relação ao capim-elefante (Tabela 1). Ressalta-se que, na silagem com $0 \%$ de farelo de cacau, o teor de NT não foi preservado, pois a forrageira, antes de ser ensilada, apresentava 1,38\% de NT e, após a abertura dos silos, apenas $0,87 \%$. Provavelmente, o baixo teor de MS do capim-elefante prejudicou a fermentação e favoreceu a proteólise no interior do silo reduzindo o teor de MS na silagem. Este fato, no entanto, não ocorreu com o capim emurchecido, pois o teor de NT foi preservado, sendo observados valores de 1,36 e 1,35\%, respectivamente, no capim-elefante emurchecido e na silagem produzida com esse capim.

Tendência semelhante foi observada para os teores de

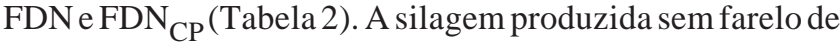
cacau (com o capim-elefante não emurchecido) apresentou maiores teores destas frações. Contudo, valores inferiores ao encontrado na silagem do capim emurchecido foram registrados nas silagens produzidas com 7, 14, 21 e $28 \%$ de farelo de cacau. A análise de regressão comprovou que a adição de farelo de cacau ao capim-elefante para produção de silagem resultou em diminuição linear nos teores de FDN e FDN $_{\mathrm{CP}}$ (Tabela 3), o que pode ser atribuído aos menores teores desses constituintes no farelo de cacau em relação ao capim-elefante.

Como demonstrado na Tabela 2, o teor de FDA das silagens produzidas com 0 e $7 \%$ de farelo de cacau foi superior ao obtido na silagem do capim emurchecido $(\mathrm{P}<0,05)$. No entanto, as silagens com 14, 21 e $28 \%$ de farelo de cacau apresentaram valor similar ao encontrado naquela produzida com capim emurchecido. Considerando apenas os níveis de inclusão de farelo de cacau ao capim-elefante, o teor de FDA das silagens sofreu efeito quadrático $(P<0,05)$, sendo estimado valor mínimo de $47,0 \%$ para o nível de $20,5 \%$

Tabela 2 - Composição química (valores médios) e digestibilidade in vitro da MS (DIVMS) da silagem de capim-elefante emurchecido (EMUR) e das silagens do capim-elefante não emurchecido adicionadas de farelo de cacau

Table 2 - Chemical composition (mean concentrations) and in vitro DM digestibility (IVDMD) of elephantgrass silages wilted (WIL) and not wilted with cocoameal

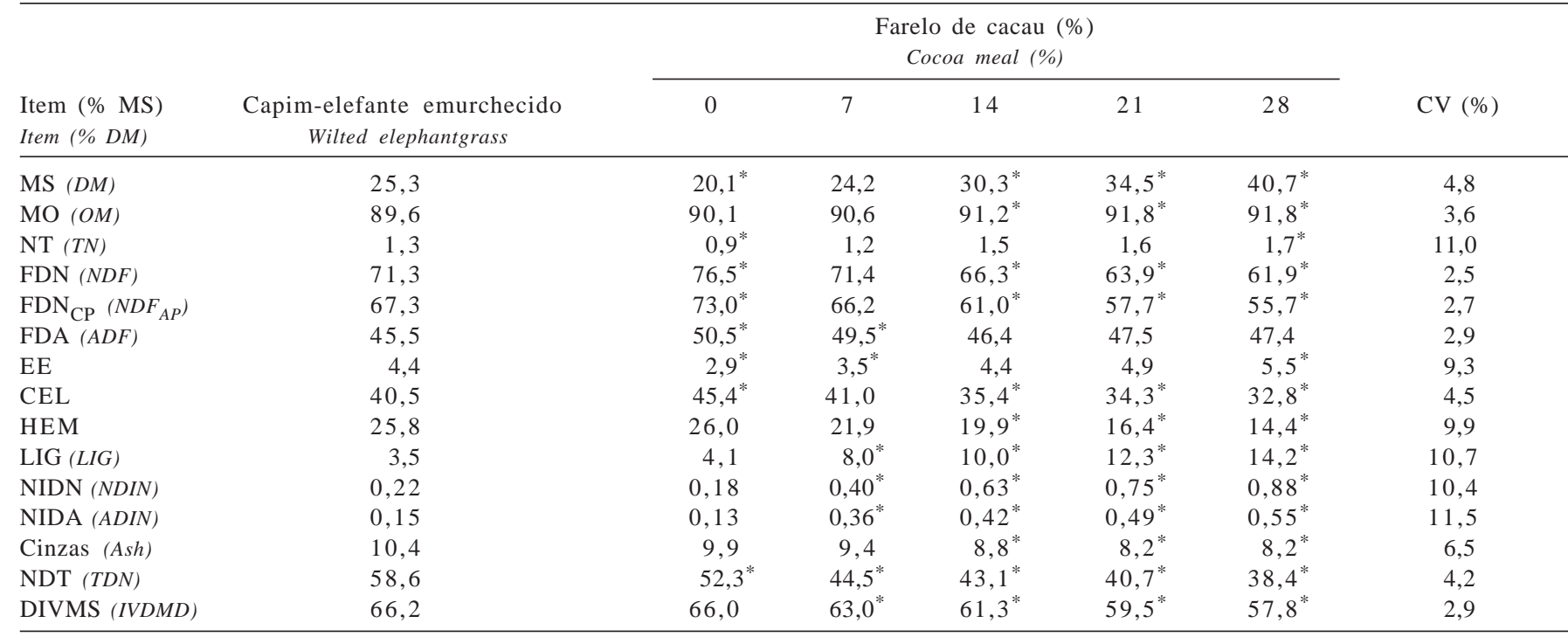

*Médias seguidas por asterisco diferem da testemunha a 5\% de probabilidade pelo teste de Dunnett.

* Means followed by asterisk differ from the control at $5 \%$ probability level by Dunnett test. 
Tabela 3 - Composição nutricional de silagens produzidas com farelo de cacau e capim-elefante não emurchecido Table 3 - Chemical composition of elephantgrass silages as a function of cocoa meal addition levels and wilting process

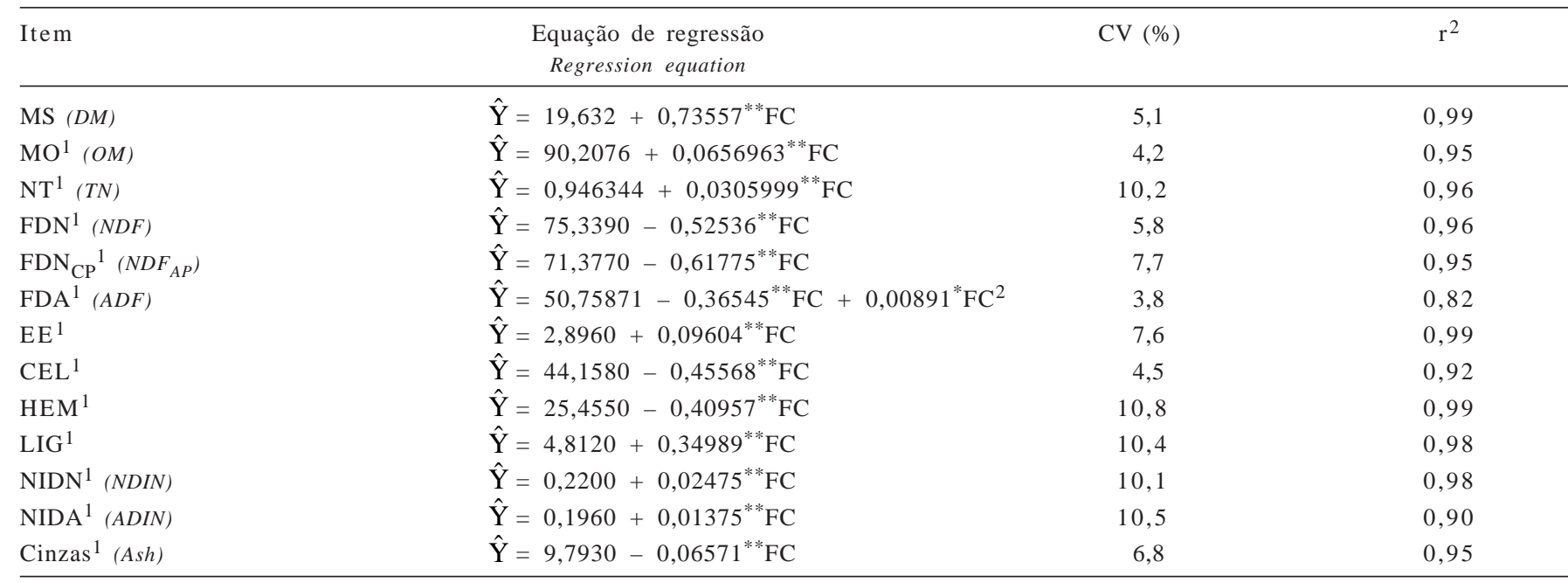

* Significativo a $5 \%$ de probabilidade pelo teste $\mathrm{F}$ (Significant at $5 \%$ probability, by $\mathrm{F}$ test).

** Significativo a $1 \%$ de probabilidade pelo teste $\mathrm{F}$ (Significant at $1 \%$ probability, by $\mathrm{F}$ test).

$1 \%$ da MS (DM \%).

de farelo de cacau. Essa resposta é de difícil explicação, pois o farelo de cacau possui teor de FDA (40,1\%) semelhante ao do capim-elefante (43,7\%); assim, esperava-se pequena redução ou nenhuma alteração desta fração nas silagens.

A análise estatística dos valores de extrato etéreo (EE) comprovou diferenças $(\mathrm{P}<0,05)$ entre a silagem produzida com o capim-elefante emurchecido e com adição de 0,7 e 28 de farelo de cacau. Os teores de EE das silagens com $14 \mathrm{e}$ $21 \%$ de farelo de cacau foram semelhantes ao da silagem de capim emurchecido. A adição de farelo de cacau ao capimelefante promoveu aumento linear $(\mathrm{P}<0,01)$ no teor de $\mathrm{EE}$ das silagens, provavelmente em decorrência do maior conteúdo deste nutriente no farelo de cacau.

O teor de celulose da silagem produzida com $7 \%$ de farelo de cacau foi similar $(\mathrm{P}>0,05)$ ao daquela produzida com capim-elefante emurchecido. Entretanto, as silagens produzidas com capim-elefante e $0,14,21$ e $28 \%$ de farelo de cacau diferiram significativamente da silagem produzidas apenas com o capim emurchecido.

As silagens com 0 e $7 \%$ de farelo de cacau apresentaram teores de hemicelulese similares ao da silagem de capim emurchecido. No entanto, a partir do nível de $14 \%$ de farelo de cacau, as concentrações de hemicelulose foram inferiores à obtida para a silagem produzida com capim-elefante emurchecido (Tabela 2).

Tanto o teor de celulose quanto o de hemicelulose das silagens reduziram com a adição de farelo de cacau ao capim-elefante (Tabela 3), sendo observadas reduções de 9,6; 22,0; 24,4 e 27,7\% para o teor de celulose e de 15,8; 23,5; 36,9 e 44,5\% para o de hemicelulose nos níveis de 7, 14, 21 e $28 \%$ de FC, respectivamente, em relação à silagem sem farelo de cacau. Essas reduções provavelmente foram conseqüência dos baixos teores destas frações no farelo de cacau ( $23,1 \%$ de celulose e $8,5 \%$ de hemicelulose).

Apenas a silagem produzida com capim-elefante sem farelo de cacau apresentou teor de lignina similar ao da silagem produzida com capim emurchecido. Os valores obtidos nas demais silagens $(7,14,21$ e $28 \%$ de farelo de cacau) foram estatisticamente superiores aos da silagem com capim emurchecido. Os elevados teores de lignina nas silagens produzidas com farelo de cacau podem ter decorrido do alto valor desta fração no farelo de cacau (17,9\%), o que explica o aumento linear $(\mathrm{P}<0,01)$ dos teores de lignina na silagem com o acréscimo dos níveis de farelo de cacau.

A tendência para os valores de NIDN e NIDA (Tabela 2) foi semelhante, pois apenas a silagem produzida com capimelefante e $0 \%$ de farelo de cacau apresentou teores destas frações similares ao da silagem com capim emurchecido. Os valores de NIDN e NIDA nas silagens produzidas com 7, 14, 21 e $28 \%$ de farelo de cacau foram superiores $(\mathrm{P}<0,05)$ aos obtidos na silagem produzida com capim emurchecido. $\mathrm{O}$ estudo da regressão revelou efeito linear crescente dos níveis de farelo de cacau sobre os teores de NIDN e NIDA das silagens (Tabela 3). Segundo McDonald et al. (1991), o aquecimento da massa ensilada com a fermentação no interior do silo contribui para a elevação dos teores destas frações. Contudo, o aumento dos teores de NIDN e NIDA nas silagens pode ser explicado pelos maiores valores destes componentes no farelo de cacau em relação ao capim-elefante no momento da ensilagem (Tabela 1). Os 
valores estimados pela equação de regressão (Tabela 3) foram de 0,$22 ; 0,39 ; 0,56 ; 0,74$ e $0,91 \%$ de NIDN e de 0,$20 ; 0,29$; 0,38; 0,48 e 0,58\% de NIDA, respectivamente, para os níveis de $0,7,14,21$ e $28 \%$ de farelo de cacau. Do ponto de vista nutricional, não é desejável aumento nos teores de NIDA, pois o nitrogênio retido na FDA é indisponível aos microrganismos ruminais (Van Soest, 1994).

O teor de NDT das silagens produzidas com farelo de cacau foi inferior $(\mathrm{P}<0,05)$ ao da silagem com capim emurchecido (Tabela 2). Observou-se redução linear no teor de NDT com o aumento dos níveis de farelo de cacau (Figura 1). O decréscimo de 0,45 unidades percentuais por unidade de farelo de cacau adicionada pode ser atribuído aos elevados teores de NIDA e lignina no farelo de cacau, pois, na estimativa do teor de NDT das silagens, obtida pela equação descrita por Weiss et al. (1992) e adaptada pelo NRC (2001), consideram-se a PB verdadeiramente digestível, calculada a partir da fração de proteína retida na FDA, e a FDN verdadeiramente digestível, que, entre outras frações, inclui o teor de lignina da forragem.

Estudando a eficácia das equações propostas pelo NRC (2001) para avaliação energética de alimentos, Rocha Jr. (2002) compilou diversos valores de NDT disponíveis na literatura nacional, obtidos em experimentos in vivo, e os comparou a valores preditos pelas equações do NRC (2001). Esse autor não observou diferença significativa entre os valores observados e preditos, o que sugere que as equações são adequadas para predizer o valor energético dos alimentos nas condições brasileiras.

- NDT — DIVMS

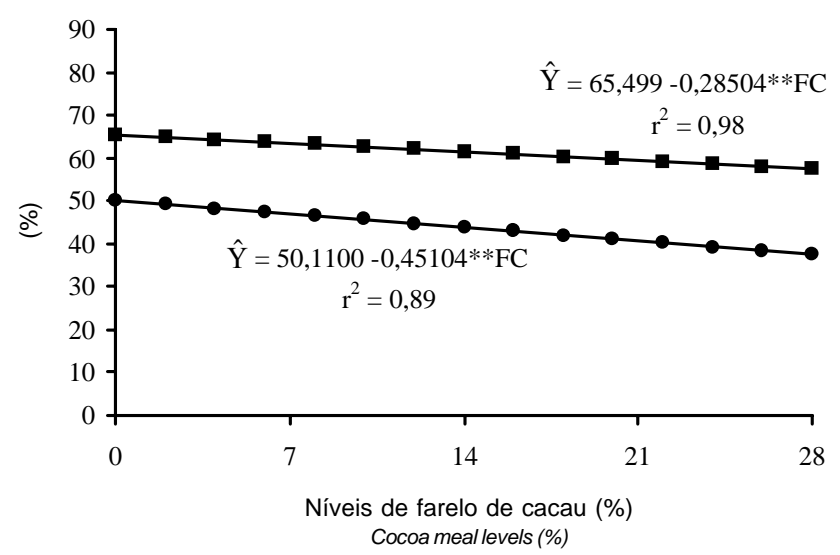

Figura 1 - Estimativa dos valores de NDT e digestibilidade in vitro da MS (DIVMS) de silagens produzidas com diferentes níveis de farelo de cacau.** Significativo a $1 \%$ de probabilidade pelo teste $\mathrm{F}$.

Figure 1 - Estimate of total digestible nutrients (TDN) and DM in vitro digestibility (IVDMD) of silages as a function of different cocoa meal (CM) levels. ** Significant at $1 \%$ probability by $F$ test.
Rocha Jr. et al. (2003), avaliando a estimativa do valor energético de alimentos e a validação das equações propostas pelo NRC (2001), observaram valor de NDT predito da silagem de capim-elefante de $50,6 \%$, próximo ao obtido neste estudo (52,3\%) na silagem com $0 \%$ de farelo. Menor estimativa do teor de NDT $(44,8 \%)$ foi relatada por Rodrigues et al. (2001) em estudo sobre o valor nutritivo do capimelefante (Pennisetum purpureum, Schum). Esses resultados se devem, provavelmente, ao estádio de maturação mais avançado do capim utilizado pelos autores (75 dias de crescimento) em relação ao utilizado neste experimento (50 dias de crescimento).

A digestibilidade in vitro da MS (DIVMS) observada para a silagem produzida sem farelo de cacau (66,0\%) foi similar $(\mathrm{P}>0,05)$ à obtida para a silagem com o capimelefante emurchecido (66,2\%). As silagens produzidas com capim-elefante e farelo de cacau apresentaram DIVMS inferior à da silagem de capim emurchecido (Tabela 2). É possível que a redução na DIVMS das silagens com farelo de cacau tenha decorrido da composição desse subproduto, que apresentou elevado teor de lignina, um composto fenólico nutricionalmente indigestível pelos microrganismos ruminais.

A adição de níveis crescentes de farelo de cacau ocasionou redução linear na DIVMS das silagens (Figura 1) e decréscimo de $0,28 \%$ por unidade de farelo de cacau adicionada ao capim-elefante. Estimados pela equação de regressão (Figura 1), os valores de DIVMS para as silagens com $0,7,14,21$ e $28 \%$ de farelo de cacau foram, respectivamente, 65,$5 ; 63,5 ; 61,5 ; 59,5$ e $57,5 \%$, semelhantes aos encontrados por Bernardino et al. (2005), que, estudando a adição de casca de café (0, 10, 20, 30 e 40\%) na ensilagem do capim-elefante, observaram redução linear da DIVMS das silagens. Do mesmo modo, Souza et al. (2003) também avaliaram silagens de capim-elefante e casca de café $(0$; 8,7; 17,4; 26,1 e 34,8\%) e registraram decréscimo linear da DIVMS conforme aumentaram os níveis de casca de café.

\section{Conclusões}

Embora não seja viabilizado em grande escala, o emurchecimento do capim-elefante pela exposição ao sol reduz o teor de umidade da forragem e permite a produção de silagem de bom valor nutritivo.

O farelo de cacau pode ser considerado um bom aditivo para absorção da umidade na ensilagem de capim-elefante, entretanto, diminui o valor nutritivo das silagens.

A adição de farelo de cacau na ensilagem de capimelefante pode ser feita em níveis de até $14 \%$, pois níveis mais 
elevados deste subproduto reduzem a digestibilidade in vitro das silagens para valores menores que $60 \%$.

A utilização de farelo de cacau na ensilagem de capimelefante reduz o teor de NDT das silagens.

\section{Literatura Citada}

ANDRADE, J.B. Efeito da adição de rolão de milho, farelo de trigo e sacharina na silagem de capim-elefante (Pennisetum purpureum, Schum.). Botucatu: Universidade Estadual Paulista, 1995. 190p. Tese (Doutorado em Zootecnia) - Universidade Estadual Paulista, 1995.

BERNARDINO, F.S.; GARCIA, R.; ROCHA, F.C. et al. Produção e características do efluente e composição bromatológica da silagem de capim-elefante contendo diferentes níveis de casca de café. Revista Brasileira de Zootecnia, v.34, n.6, p.21852291, 2005.

DUNNETT, C.W. A multiple comparison procedure for comparing several treatments with control. Journal American State Association, v.50, n.272, p.1096-1121, 1955.

EMPRESA BRASILEIRA DE PESQUISA AGROPECUÁRIA EMBRAPA. Sistema brasileiro de classificação de solos. Brasília: 1999. 412p.

MACHADO FILHO, L.C.P.; MÜHLBACH, P.R.F. Efeito do emurchecimento na qualidade da silagem de capim-elefante cv. Cameroun (Pennisetum purpureum, Schum.) e de milheto (Pennisetum americanum (L.) Leeke), avaliadas quimicamente. Revista Brasileira de Zootecnia, v.15, n.3, p.224-233, 1986.

McDONALD, P.; HENDERSON, A.R.; HERON, S.J.E. The biochemistry of silage. 2.ed. Marlow: Chalcombe Publications, 1991. 340p.

MUCK, R.E. Factors influencing silage quality and their implications for management. Journal of Dairy Science, v.71, n.11, p.2992-3002, 1988.

NATIONAL RESEARCH COUNCIL - NRC. Nutrient requirements of dairy cattle. 7.ed. Washington, D.C.: National Academy Press, 2001. 450p.

PELL, A.N.; SCHOFIELD, P. Computerized monitoring of gas production to measure forage digestion in vitro. Journal of Dairy Science, v.76, n.9, p.1063-1073, 1993.

ROCHA JR., V.R.; VALADARES FILHO, S.C.; BORGES, A.M. et al. Estimativa do valor energético dos alimentos e validações das equações propostas pelo NRC (2001). Revista Brasileira de Zootecnia, v.32, n.2, p.480-490, 2003.

ROCHA JR., V.R. Tabelas brasileiras de composição de alimentos, determinação e estimação do valor energético dos alimentos para ruminantes. Viçosa, MG: Universidade Federal de Viçosa, 2002. 252p. Tese (Doutorado em Zootecnia) - Universidade Federal de Viçosa, 2002.
RODRIGUES, P.H.M.; ANDRADE, S.J.T.; FERNANDES, T. et al. Valor nutritivo da silagem de capim-elefante cultivar Napier (Pennisetum purpureum, Schum) inoculada com bactérias ácidoláticas. Acta Scientiarum, v.23, n.4, p.809-813, 2001.

STATISTICAL ANALYSES SYSTEM - SAS. SAS user's guide. Cary: 1999. v.8, 295p.

SILVA, D.J.; QUEIROZ, A.C. Análise de alimentos: métodos químicos e biológicos. Viçosa, MG: Editora UFV, 2002. 235p.

SILVA, H.G.O.; PIRES, A.J.V.; SILVA, F.F. et al. Farelo de cacau (Theobroma cocoa L.) e torta de dendê (Elaeis guineensis, Jacq) na alimentação de cabras em lactação: consumo e produção de leite. Revista Brasileira de Zootecnia, v.34, n.5, p.17901798, 2005.

SOUZA, A.L.; BERNARDINO, F.S.; GARCIA, R. et al. Valor nutritivo da silagem de capim-elefante (Pennisetum purpureum, Schum.) com diferentes níveis de casca de café. Revista Brasileira de Zootecnia, v.32, n.4, p.828-833, 2003.

TOSI, H.; RODRIGUES, R.L.A.; JOBIM, C.C. et al. Ensilagem do capim-elefante cv. Mott sob diferentes tratamentos. Revista Brasileira de Zootecnia, v.24, n.6, p.909-916, 1995.

TOSI, P.; MATTOS, W.R.S.; TOSI, H. et al. Avaliação do capimelefante (Pennisetum purpureum, Schum.) cv. Taiwan A-148, ensilado com diferentes técnicas de redução de umidade. Revista Brasileira de Zootecnia, v.28, n.5, p.947-954, 1999.

Van SOEST, P.J.; ROBERTSON, J.B.; LEWIS, B.A. Methods for dietary fiber, neutral detergent fiber, and nonstarch polyssacarides in relation to animal nutrition. Journal of Dairy Science, v.74, n.10, p.3583-3597, 1991.

Van SOEST, P.J. Nutritional ecology of the ruminant. 2.ed. Ithaca: Cornell University Press, 1994. 476p.

VILELA, D. Utilização do capim-elefante na forma de forragem conservada. In: SIMPÓSIO SOBRE CAPIM-ELEFANTE, 1990, Coronel Pacheco. Anais... Coronel Pacheco: EMBRAPA Centro Nacional de Pesquisa de Gado de Leite, 1990. p.89-131.

WEISS, W.P.; CONRAD, H.R.; PIERRE, N.R.S. A theoreticallybased model for predicting total digestible nutrient values of forages and concentrates. Animal Feed Science and Technology, v.39, p.95-110, 1992. 